\title{
Idiopathic Cardiomyopathy
}

National Cancer Institute

\section{Source}

National Cancer Institute. Idiopathic Cardiomyopathy. NCI Thesaurus. Code C53654.

A disease of the heart muscle or myocardium proper whose cause is unknown. 